\title{
Work Locus of Control as a Moderator of Relationship between Work Stressor and Counter Productive Work Behavior
}

\author{
SHAHNAZ AKHTAR ${ }^{1}$, MUTAYYABA MAJEED ${ }^{2}$, SADIA AMAN ${ }^{3}$, SYEDA SARA BANO ${ }^{4}$, SUBHAN ULLAH ${ }^{5}$, NOOR-I-KIRAN NAEEM ${ }^{6}$ \\ ${ }^{1}$ Senior Subject Specialist Psychology, Bhaudin zikrya University, Multan \\ ${ }^{2}$ Senior Lecturer Physiology Independent Medical College, Faisalabad \\ ${ }^{3}$ Senior Lecturer Anatomy, Islamabad Medical and Dental College, Islamabad \\ ${ }^{4}$ Assistant Professor Anatomy Department, Shifa College of Medicine, Islamabad \\ ${ }^{5}$ PsychiatryAssistant Professor, Aziz Fatimah Medical College, Faisalabad \\ ${ }^{6}$ Assistant Professor Medical Education, Dr. Rehmatullah's Hospital, Gojra \\ Corresponding author: Sadia Aman, Email: dr.sadiagm@gmail.com, Cell: +923336070532
}

\begin{abstract}
Purpose: This study was conducted to determine whether the work locus of control is a moderator of the relationship between counterproductive behavior at work and work stressors.

Methods: To investigate this relationship, 346 full-time working adults employed at Nishter hospital Multan and Allied hospital Faisalabad were surveyed during the period from January 2019 to January 2020 via three checklist questionnaires. Using hierarchical regression analysis, both main and moderator effect were tested in order to determine whether work locus of control influence employee's tendencies engage in counterproductive behavior in response to work stressors.

Results: Shows that the work locus of control interacts significantly with work stressors in predicting counterproductive behavior at work, suggesting that the work locus of control is an important variable to consider when studying productive behavior at work. The implications of these findings and ideas for future research are discussed.

Conclusion: CWB has a detrimental effect on organizations and individuals related with the organization; therefore, organizations should be attentive of the probable influences influencing employee participation in CWB.

Keywords: Counterproductive behavior at work, Deviations in the workplace, Location of control in the workplace, Stress at work, Personality
\end{abstract}

\section{INTRODUCTION}

Counterproductive behavior in the workplace or in CWB denotes to deliberate behavior by workers that troubles organization members or the organization itself (Rotundo Spector, 2010). If a worker is not present at work due to ailment or a family reserve, this must not deliberate as CWB. The employee's absence made difficult for the supervisor or co-worker is considered the employee's absence.

Absence from your job can often have undesirable significances. But the varianceamid the two instances mentioned above is that the $1^{\text {st }}$ is the involuntary absence and the second is deliberate absence. Moreover, if it is found that an employee is trying to achieve better job performance, CWB does not cover poor job performance. The reason why an employee is not doing well is simply because there is no such possibility and ability. If an employee deliberately slows down while working, poor performance can be considered CWB (Rotundo and Spector, 2010).

Personality factors and work stress are clearly related variables because they affect employees. Personality can impact how a worker responds and interprets to the various work-related stresses they practice. The two variables are associated as personality can impact the method employees interpret and retort to work stressors. Current studies have shown that personality can be measured a probable moderator in the associationamid the CWB and work stressor (eg Bowling and Eschleman, 2010). This ensures that it is significant to study the interactive impacts of personality and work stressors in the CWB.

McCrae and Costa (1987) introduced the five-factor model of personality. It is also known as to pays close attention how personality can be related with CWB. Various analysis has provided suggestion that the five major proportions are related to CWB (for example, Salgado, 2002) and that some proportions of the five major dimensions may be differently related to CWB-I and CWB-O in a study by Mount et al., 2006.

Rotter in 1990 shows that the LOC refers to the degree at which individuals believe they have control over the events that affect them. It is usually divided into external and internal LOCs. Individuals with a high internal LOC, also known as internal, have faith in that the results are their own actions and behavior, while those with a high external LOC classified as externalshave faith that the results are the result of fate or luck. It is dependent on other people or areunpredictable (Rotter, 1990).
Problem statement: There is a serious problem with the emergence of counterproductive work-related behavior in the Punjab hospitals in Pakistan. In addition to productive behavior at work, employees also exhibit counter-productive behavior at work. Possible reasons for this behavior are a large power distance in management, high burnout and widespread exclusion from the workplace.

Taking into account the existing literature and theories, the following hypotheses were formulated.

1 Workplace stressors will be positively associated with counter-productive behavior at work.

2 Workplace stressors will be related to the work locus of control.

3 Work locus control will look at unproductive behavior at work.

$4 \quad$ Maintaining work locus control will make it easier to link stress at work with counterproductive behavior at work.

\section{MATERIAL AND METHODS}

Participants in this study were engaged from a group of full-time nursing and teaching staff from university hospitals in Punjab, Pakistan. 346 potential participants were selected using a questionnaire adapted from Sprung (2011). Among these participants, 177 completed questionnaires were used for analysis of data, with a $43 \%$ response rate. The investigatoralienated the contributors into 3 main groups, i.e., the participants age was 21 $29(38.3 \%), 30-45(51.4 \%)$ and $40>(10 \%)$ years, with a S.D of $25.88,43.16$ and 47.89 , respectively. The usual work experience of the participants was 8.5 years with 6.3 S.D. Most of the members are men (54.2\%). The occupations represented in this sample were health departments and teaching or nursing staff.

Subsequently the Levene's test statisticvalue of is less than the critical value, we do not reject the null hypothesis at a 0.05 value which was quitesignificance (see Table 5). The one-way anovaresultsshowed no substantialvarianceamong females and males, $F(1,175)=0.306, p>0.05$.

Instruments: The Spector WLC scale (shortened form) (i.e. the standard value is $\alpha=0.72$ ) was used to measure the working LOC (Spectron 1988). Employs CW evolution comprised with a total of 8 items. Half of the elements mirror the external LOC and the other half the inner LOC. 
Table 1: Demographics

\begin{tabular}{|l|l|l|l|}
\hline & Frequency (N) & Percentage (\%) & Mean \pm SD \\
\hline Age & & & \\
\hline $21-29$ & 46 & 38.3 & $25.88 \pm 2.293$ \\
\hline $30-45$ & 62 & 51.7 & $34.16 \pm 2.919$ \\
\hline $40>$ & 12 & 10 & $47.89 \pm 6.846$ \\
\hline Sex & & & \\
\hline Male & 96 & 54.2 & \\
\hline Female & 81 & 45.8 & \\
\hline $\begin{array}{l}\text { Job Tenure } \\
\text { (years) }\end{array}$ & & & $6.21 \pm 6.825$ \\
\hline $0-10$ & 100 & 82.6 & \\
\hline $20-$ Nov & 13 & 10.7 & \\
\hline $21-30$ & 8 & 6.6 & \\
\hline
\end{tabular}

Table 2.Test of homogeneity of variances

\begin{tabular}{|l|l|l|l|l|}
\multirow{2}{*}{ Work stress } & LeveneStatistic & $\mathrm{df} 1$ & $\mathrm{df} 2$ & Sig. \\
\cline { 2 - 5 } & 2.897 & 1 & 175 & 0.091 \\
\hline
\end{tabular}

Counter-productive behavior at work: A CWB 33-point checklist (i.e., standard value of $\alpha=0.9$ ) was used to measure CWB (Spector et al., 2006). A multifaceted CWB score will represent behavior in all of these metrics, providing future clues for any organizational setting, such as " guidance for people in the workplace" or information about situational behavior.

Work Stress: By the quantitative workload inventory of Jexand Spector (1998) (ie, standard value $\alpha=0.89$ ); Workload was measured. This scale includes five items that measure the amount of work that the participant has to do in the workplace. Each item is an expression of the participant's effort.

A questionnaire of approximately 20 minutes was used which confined the demographic information and variables from the questionnaire. Before responding to the questionnaire, participants were requested to accept and sign informed consent. Participants were then completed a questionnaire, starting by entering their contact number and name as an identification form. I have received a contact number to confirm additional procedures. Participants were also enquired to provide demographic information to compare and separate respondents. After this procedure, the respondent's name becomes an anonymous identity to protect the identity of the participants.

\section{RESULTS}

Table 3.Crosstabs

\begin{tabular}{|l|l|l|l|l|l|l|}
\hline \multirow{5}{*}{} & & Valid & & Missing & & Total \\
\cline { 2 - 7 } & $\mathrm{N}$ & $\%$ & $\mathrm{~N}$ & $\%$ & $\mathrm{~N}$ & $\%$ \\
\cline { 2 - 8 } & & & & & & \\
\cline { 2 - 7 } $\begin{array}{l}\text { Work stress } \\
\text { CBW }\end{array}$ & 177 & 51.2 & 169 & 48.8 & 346 & 100 \\
\hline
\end{tabular}

Additionally, we performed the Shapiro-Wilk normality tests and the data appears to be normally dispersed as it trails the diagonal line and does not seem to have a non-linear pattern, $p>$ 0.05 . There was a statistically significant, moderately positive correlation between the scores on both scales, $r=0.233, p<0.5$ and 0.001 , which designates that stress at work is significantly positively connected to counterproductive behavior at work.

Table 2.Descriptive statistics for Work related stress and Work locus of control

\begin{tabular}{|l|l|l|l|}
\hline & Mean & Std. Deviation & N \\
\hline Work stress & 3.6186 & .6506 & 177 \\
\hline Work locus & 4.8333 & .4082 & 177 \\
\hline
\end{tabular}

This time Spearman's rho was used because the locus scale data exhibited no linearity. According to the results of the analysis, the word locus of control (internal-external) was significantly associated with occupational stressors, and the relationship was positive, $r s=0.204, p<0.05$. Our $2^{\text {nd }}$ hypothesis was also established.

Table 4: Partial correlations
\begin{tabular}{|l|l|l|l|l|}
\hline $\begin{array}{l}\text { Control } \\
\text { variables }\end{array}$ & & & Workstress & CWBC \\
\hline \multirow{4}{*}{ Locus total } & & & & \\
\cline { 2 - 5 } & Workstress & Correlation & 1 & 0.498 \\
\cline { 2 - 5 } & & $\mathrm{p}$ &. & $.000^{*}$ \\
\cline { 2 - 5 } & & $\mathrm{df}$ & 0 & 176 \\
\cline { 2 - 5 } & & & 0.498 & 1 \\
\cline { 2 - 5 } & $\mathrm{CWBC}$ & Correlation & $.000^{*}$ &. \\
\cline { 2 - 5 } & & $\mathrm{p}$ & 176 & 0 \\
\cline { 2 - 5 } & & $\mathrm{df}$ & 170 & \\
\hline
\end{tabular}

After analyzing the overall score of the CWB scale, together with the work stress and the work locus of control, we wanted to see how the CWB subscales relate to these variables. We found two dimensions represented in the CWB organization subscale and the CWB-person subscale. As can be seen in Table 3, we find many different correlations. The organization of CWB was positively and significantly correlated with CWB employees, work stress and the CWB aggregate. The CWB subjects only had a significant and positive relationship with CWB-org, but still had a strong positive relationship with the worklocus and a very weak relationship with workstress.

Table 5: Correlations

\begin{tabular}{|l|l|l|l|l|l|}
\hline & $\begin{array}{l}\text { CWB- } \\
\text { org }\end{array}$ & $\begin{array}{l}\text { CWB- } \\
\text { pers }\end{array}$ & $\begin{array}{l}\text { Work } \\
\text { locus }\end{array}$ & $\begin{array}{l}\text { Work } \\
\text { stress }\end{array}$ & $\begin{array}{l}\text { CWB- } \\
\text { total }\end{array}$ \\
\hline CWB-org & 1 & $.171^{\star}$ & -0.27 & $.257^{* *}$ & $.284^{* *}$ \\
\hline CWB-pers & $.171^{*}$ & 1 & 0.488 & 0.02 & 0.121 \\
\hline Work locus & -0.27 & 0.488 & 1 & $.204^{*}$ & 0.174 \\
\hline Work stress & $.257^{\star *}$ & 0.02 & $.204^{\star}$ & 1 & $.233^{\star}$ \\
\hline CWB-total & $.284^{\star *}$ & 0.121 & 0.174 & $.233^{*}$ & 1 \\
\hline
\end{tabular}

Note: * the correlation is significant at the 0.05 level. ** correlation is significant at the level of 0.01

The next pair of analyzes were aimed at answering questions about probable differences amid the groups. In the initial analysis, our dependent variable on the one-way ANOVA was the level of occupational stress and our independent variable was the age of the participant at three levels (see Table 4). We found no major effects for the age under study $F(2,120)=1.004, p>0.05$

Table 6: Demographic

\begin{tabular}{|c|c|c|c|}
\hline & Frequency $(\mathrm{N})$ & Percentage (\%) & Mean \pm SD \\
\hline \multicolumn{4}{|l|}{ Age } \\
\hline $21-29$ & 46 & 38.3 & $25.88 \pm 2.293$ \\
\hline $30-45$ & 62 & 51.7 & $34.16 \pm 2.919$ \\
\hline $40>$ & 12 & 10 & $47.89 \pm 6.846$ \\
\hline \multicolumn{4}{|l|}{ Sex } \\
\hline Male & 96 & 54.2 & \\
\hline Female & 81 & 45.8 & \\
\hline $\begin{array}{l}\text { Job Tenure } \\
\text { (years) }\end{array}$ & & & $6.21 \pm 6.825$ \\
\hline $0-10$ & 100 & 82.6 & \\
\hline 20-Nov & 13 & 10.7 & \\
\hline $21-30$ & 8 & 6.6 & \\
\hline
\end{tabular}

We conducted our third one-way ANOVA to control the differences between participants' counterproductive behavior at work and gender. We found significant results, $F(1175)=41.879$, $p<0.01$. If we look closely at the results, we can see that the women in our sample (mean $=3.3519$, SD $=0.8819$ ) showed significantly higher levels of counterproductive behavior at work than men $($ mean $=2.3854, S D=1.07233)$.

\section{DISCUSSION}

In this study, we first tried to answer 4 questions. $1^{\text {st }}$, the investigator tried to investigate the nature of the associationamid work stress and self-deprecating behavior. It was assumed that the association between them would be relatedpositively and such anoutcome was originated. As counterproductive behavior denotes to employee behavior that harms their workplaces and 
organizations, it is believed that high levels of stress in the workplace will be associated with high levels of unproductive behavior, and the data suggest such an association. Though moderate, this substantial association presented us that high levels of work stress can upsurgecounter-productive behavior. In other words, increased work-related stress is related with an increase in self-destructive behavior. This is a phenomenon that should be addressed in future research.

All these results suggest that we should use more scales and factors to explore the true nature and consequences of selfdestructive behavior in future research. This behavior can lead to more serious and permanent problems in the workplace. Monitoring and analyzing this data can be vital in adequately helping people with high levels of stress and self-destructive behaviors.

One possible explanation for the relationship between a functioning LOC and CBWB is that people with an outside LOC may attempt to change their environment and upsurge their sense of control by resorting to destructive activities (Allen and Greenberger, 1980). Once frustrated, staffs working outside the LOC can use any CWB to control their environment. These destructive actions can help the employee avoid feeling helpless. In turn, trainees can find more productive ways to deal with frustration, such as communicating with a supervisor or a colleague. This means that CWB can function as a method for outsiders to increase their perception of control over their work environment.

Finally, it has been suggested that LOC at work is moderately related to stress at work and the NEO. It has been hypothesized that a higher level of work-related stress is associated with an upsurge in both CWBforms, and the consequence will be stronger in the case of people outside the workplace.

Limitations: Application of the self-report measure, cross-section design

\section{CONCLUSION}

CWB has anunfavorable effect on organizations and persons related with the organization; Therefore, organizations should be conscious of the probable reasons influencing employer participation in CWB. This analysis delivers the first indication that the LOC study is a significant variable to ponder for CWB; The LOC of the work showed significant CWB effects as well as interactions with occupational stressors in forecasting CWB even afterward governing the overall LOC. As this study results are counterintuitive and different from preceding analysis, upcoming studies are fortified to wholly comprehend the role of the LOC study in predicting CWB.

\section{REFERENCES}

1. Grinley, Amanda. "Empathy as a Buffer: The Moderating Effect of Trait Empathy on Counterproductive Work Behavior." (2021).

2. Kayani, Muhammad Bilal, and Imran Ibrahim Alasan. "Impact of Toxic Leadership on Counterproductive Work Behavior with the Mediating role of Psychological Contract Breach and Moderating role of Proactive Personality." Studies of Applied Economics 39, no. 4 (2021).

3. Newton, Chad, and Richard Perlow. "The Role of Leader-Member Exchange Relations and Individual Differences on Counterproductive Work Behavior." Psychological Reports (2021): 0033294121989298.

4. Ahmed, Ishfaq, Talat Islam, Saima Ahmad, and Ahmad Kaleem. "A COVID-19 contextual study of customers' mistreatment and counterproductive work behavior at coffee cafés." British Food Journal (2021)

5. Gürlek, Mert. "Workplace ostracism, Syrian migrant workers' counterproductive work behaviors, and acculturation: Evidence from Turkey." Journal of Hospitality and Tourism Management 46 (2021): 336-346.

6. Songa, Isaac Raj, MrPrajwalSalins, MrKamathMadhusudana, RajibMandal, and MrBijuSomanMsAswathi Raj. "Conceptualising Hypotheses for the Effects of Organisational Structure on Faculty Job Performance, Job Satisfaction and Counterproductive Work Behavior through a Comprehensive Literature Review." Psychology and Education Journal 58, no. 2 (2021): 2855-2866.

7. Cahyadi, Ani, HendryadiHendryadi, and AgoestinaMappadang "Workplace and classroom incivility and learning engagement: the moderating role of locus of control." International Journal for Educational Integrity 17, no. 1 (2021): 1-17.

8. Karina, Sayapina. "Counterproductive Work Behavior in Russian Nanotechnology Organizations." Psychology in Russia: State of the art 14, no. 1 (2021): 49-68.

9. Zhu, Jinqiang, Hongguo Wei, Hai Li, and Holly Osburn. "The paradoxical effect of responsible leadership on employee cyberloafing: A moderated mediation model." Human Resource Development Quarterly (2021).

10. Ali, Rasha M. Nagib, HebaDakrory Ali, and Safaa Mohammed Zaki. "Effect of occupational adjustment on nurse's counterproductive work behavior and job burnout." Assiut Scientific Nursing Journal 9, no. 24 (2021): 51-61.

11. Laila, Anita, and SabeenNaeem Khan. "A SYSTEMATIC REVIEW REFLECTING ORGANIZATIONAL INJUSTICE AND EMPLOYEES'WORKPLACE DEVIANCE: UNLOCKING THE INFLUENCE OF EMOTIONAL EXHAUSTION." BUJHSS 4, no. 1 (2021): 17-17.

12. Singh, Riann. "'Reluctant stayers do not get what they want": the relationship between procedural injustice and workplace incivility." International Journal of Emerging Markets (2021).

13. Stoica, Ana Alexandra. "Dark Triad, Risk Taking and Counterproductive Work Behavior in Different Organizational Contexts." StudiaDoctoralia 12, no. 1 (2021): 4-19.

14. Turksoy, Selcen, and OzkanTutuncu. "An analysis of the relationship between work engagement, work locus of control, passion, and parasitism in coastal hotels." European Journal of Tourism Research 29 (2021): 2912-2912.

15. Joshi, Meha, Girish Chandra Maheshwari, and RajanYadav. "The link between employee career orientation, career management practices, citizenship behavior and gender: a moderated mediation model." Kybernetes (2021).

16. Sarwar, Aisha, Lakhi Muhammad, and Marianna Sigala. "Unraveling the complex nexus of punitive supervision and deviant work behaviors: findings and implications from hospitality employees in Pakistan." International Journal of Contemporary Hospitality Management (2021).

17. Jabeen, S., F. Sheraz, S. Haider, S. Iqbal, S. Jahan, ShehnazTehseen, and T. Hussaini. "The nexus between global disruption due to the covid-19 and performance of the construction project." Management Science Letters 11, no. 6 (2021): 1871-1880.

18. Vossen, Juul, and JoeriHofmans. "Relating within-person personality variability to organizational citizenship behavior and counterproductive work behavior: A resource-based perspective." European Journal of Personality (2021): 08902070211005623.

19. Masale, Refilwe, Emmerentia N. Barkhuizen, Nico E. Schutte, and Lidewey van der Sluis. "Relating job satisfaction and organisational commitment: The moderating and mediating roles of positive individual strengths." SA Journal of Industrial Psychology 47 (2021): 12.

20. Andel, Stephanie, ShaniPindek, and Maryana L. Arvan. "Bored, angry, and overqualified? The high-and low-intensity pathways linking perceived overqualification to behavioural outcomes." European Journal of Work and Organizational Psychology (2021): 1-14.

21. Graham, Baylor. "Off to a Poor Start: The Role of Childhood Adversity in Employee Burnout, Turnover, Commitment, and Counterproductive Behavior." PhD diss., Clemson University, 2021.

22. O'Brien, Kimberly E., Jeremy A. Henson, and Bernard E. Voss. "A trait-interactionist approach to understanding the role of stressors in the personality-CWB relationship." Journal of Occupational Health Psychology (2021).

23. Saleh, Mohammed, Murtala Ibrahim Aminu, and Maryam Mustapha. "Time Management Behaviours and Job Performance: A Conceptual Paper on Moderating Role of Job Autonomy." FUDMA JOURNAL OF MANAGEMENT SCIENCES 4, no. 1 (2021): 484-499.

24. Srivastava, Shalini, and VartikaKapoor. "Coping stress for psychological well-being: role of locus of control and demographic variables." International Journal of Indian Culture and Business Management 22, no. 2 (2021): 195-212.

25. Bani-Hani, Manar Ali, and Ayman M. Hamdan-Mansour. "The moderation effect of locus of control on the relationship between job demand and job satisfaction among nurses." International Journal of Nursing Practice 27, no. 1 (2021): e12876. 